\title{
आधुनिक युग में कम्पयूटर की भूमिका
}

\author{
डॉ. श्रुति होऱा
}

असिस्टैंट प्रोफेसर, पी.जी.जी.सी.जी, सैक्टर-11, चण्डीगढ़

विज्ञान की अनेक नयी-नयी उपलब्धियों में कम्पयूटर का विशेष स्थान है। आधुनिक युग की सब से बड़ी देन यही यन्त्र है जो मनुश्य के दिमाग से भी ज्यादा तेज कार्य करता है। यदि हम किसी विशय के बारे में सोचते है तो हमारी सोच से भी कुछ आगे हो कर पलक झपकते ही कम्पयूटर उस विषय के बारे में जानकारी दे देता हैं दूरदर्शन, आकाशवाणी किसी भी प्रकार के प्रसारण में कम्पयूटर का महत्वपूर्ण योगदान है। यह शिक्षक और विद्यार्थी तथा शोधकर्ता के लिए बहुत बड़ी उपलब्धि है। हम अपने क्षेत्र से कितना भी दूर क्यों न हो या कितनी भी दूर की जानकारी क्यों न चाहते हों चाहे वह संगीत के विषय में हो अथवा किसी अन्य विषय के बारे हो कम्पयूटर द्वारा प्राप्त कर सकते हैं। कम्प्यूटर ही एक ऐसा ज्ञानवर्धक उपकरण है। जिससे हम जानकारी प्राप्त करके अपने ज्ञान में वृद्धि तथा गलती को सुधार सकते हैं।

कम्प्यूटर मनुष्य की बुद्धि की तरह ही काम करता है। परन्तु यह बुद्धि की गति से बहुत ज्यादा तीव्र एवं उससे कई गुणा तेज काम करता है। जो समय मनुष्य सोचने में लगायेगा उसी समय में कम्पयूटर उस कार्य को और साथ ही, कई और कार्यो को कर देगा। मनुष्य मस्तिष्क एक सीमा तक बातों को याद रख सकता है परन्तु कम्पयूटर असीमित समय तक बातों को याद रख सकता है। आज दूरदर्शन, आकाशवाणी तथा अन्य प्रसारणों का संगीत के क्षेत्र में बहुत महत्व है, इन प्रसारणों में कम्पयूटर का योगदान बहुत ही महत्वपूर्ण है। यह संगीत, संगीत शिक्षण, और शोधकर्ताओं के लिए बहुत ही बड़ी और अच्छी उपलब्धि है। कम्पयूटर के माध्यम से हम दूर के स्थान, यहाँ तक अन्य देश के संगीत व संगीतकारों के बारे में बहुत आसानी से ज्ञान प्राप्त कर सकते हैं कम्पयूटर के माध्यम से हम अपने संगीतकारों की रचनाए सम्भालकर रख सकते है और जब चाहें जहां चाहें सुन सकते है व उसके बारे में विद्यार्थियों को भी जानकारी दे सकते है। 
कम्पयूटर के द्वारा प्रभावी सम्पादन, रिकार्डिंग, रिमिक्सिंग जैसे काम हजारों रूप में किये जा सकते हैं। एक ही समय में कई वाद्य यन्त्रों को सुना जा सकता है। इन्टरनेट वेबसाईट आदि इस प्रौद्योगिकी युग के अत्यन्त उपयोगी उपकरण है। कम्पयूटर से वाद्य यन्त्रों को जोड़ना और उन्हें संचालित करना पूरी तरह से तकनीकी ट्रिक्स हैं। इस कम्पयूटरी भाषा को समझने के लिए एक संचार प्रोटोकाल विकसित किया गया है, जिसे म्यूजिकल इंस्ट्रूमंट डिजिटल इन्टरफेस अर्थात् प्यार से मिडी भी कहते है। इस के द्वारा गूढ़ से गूढ़ वाद्य यन्त्रों की मनचाही ध्वनि प्राप्त कर ली जाती है। आज बाजार में काफी छोटे आकार के कम्पयूटर है जिन्हें हाथ में थामा जा सकता है व संगीत का आनन्द लिया जा सकता है। कम्पयूटर के आगमन के बाद आये इन्टरनैट ने विश्व को एक सूत्र में बाँधने का कार्य किया है।

नेटसंगीत की दुनियां का सान फोनिंग नेफ्सटर ब्लैक मैटल की वह फाईल है जिस में संगीत की स्वर-लहरियों के डिजिटल टुकड़े स्टोर किये जाते है 'नेफ्टर' जिस का निकनेम है। नेफ्टर नैट संगीत के विविध आयामों का स्र्रोत है। नेफ्टर से पहले भी नैट संगीत की फाइल थी जिसे एमपी 3 कहा जाता है। मेमोरी स्टिकवाले मोबाइल फोन जैसे किसी भी उपकरण में एम पी 3 फाइलों के इन्टरनैट से डाउनलोड किया जा सकता है। इन्टरनैट ने कई दूर-दूर के प्रयोगशालाओं को और विश्वविद्यालयों को आपस में जोड़ा हुआ है।

इस समय इन्टरनैट पर पूरे विश्व में लगभग 10 लाख वेबसाइट विद्यमान है और यह सभी वेबसाइट किसी न किसी माध्यम से सम्बद्ध है और संगीत भी इनसे जुड़ा हुआ है। इस का अर्थ है इन्टरनैट के द्वारा संगीत पूरे विश्व में आकाश की तरह फैला हुआ है।जहाँ अब तक शिक्षक केवल पढ़कर या लिखकर विद्यार्थी को शिक्षा प्रदान करते थे, वही अब विद्यार्थी स्वयं ही अपनी जिज्ञासाओं को शान्त करने के लिए इन्टरनैट के ज्ञान भंडार से ज्ञान प्राप्त कर सकते है। शोधार्थी अपने विषयों एवं रूचि के आधार पर वेबसाइट या ई-मेल द्वारा किसी बड़े कलाकार के संगीत को सुन सकते है और जानकारी प्राप्त कर सकते है। इन्टरनैट पर ऐसी बहुत सी वेबसाइट है जो संगीत सम्बन्धी सारी जानकारी उपलब्ध कराती है। कम्पयूटर व इंटरनैट ने संगीत शिक्षण तथा प्रसार में आधुनिक तकनीक प्रदान करने में कोई कमी नहीं रखी है। आषा है निकट भविष्य में संगीत बहुत उच्च स्थान ग्रहण करेगा और अपनी विशेषताओं से संसार को प्रभावित करेगा। कम्पयूटरीकृत संगीत के 
विकास ने संगीत जगत को काफी लाभान्वित किया है तथा संगीतकारों के लिए कई अवसर प्रदान किये है। कीबोर्ड, ड्रम मशीन और अन्य इलैक्ट्रानिक यन्त्रों को एक साथ जोड़ा जा सकता है। इस प्रकार के साफ्टवेयर उपलब्ध है जो एक बार में संगीत की रचना कर सकते है और कम्पयूटर सम्पूर्ण रचना को पुनः चला सकता है। इसके अतिरिक्त कम्पयूटर सिंथेसाइजर पर तैयार की गई धुनों को अधिक प्रभावी बनाया जा सकता है तथा कम्पयूटर द्वारा संगीत का प्रेशण एवं मुंद्रण भी किया जा सकता है |कम्पयूटर में जटिल प्रोग्राम की सहायता से इसके अतिरिक्त संगीत की धुन एवं राग भी पहचाने जा सकते हैं ओर सूक्ष्म से सूक्ष्म त्रुटियाँ भी ज्ञात की जा सकती है। कम्पयूटर की सहायता से संगीत की धुन भी उत्पन्न की जा सकती है। कई विदेशी फिल्मों में भी कम्पयूटर संगीत है। कम्पयूटर के माध्यम से न केवल संगीत का प्रचार अथवा प्रसार ही हुआ है बल्कि दूरस्थ शिक्षा की संभावनाओं का भी विस्तार हुआ है। इन्टरनैट ही वह माध्यम है जिससे शिष्य कुछ ही क्षणों में गुरू से सम्पर्क स्थापित कर संगीत सम्बन्धी ज्ञान प्राप्त कर सकते है, अब तो इन्टरनैट के माध्यम से गायन वादन की सभाओं में अपनी कला प्रस्तुत करने वाले कलाकारों की ध्वनि एवं उसकी प्रत्यक्ष प्रस्तुति को अत्यन्त ही सहजतापूर्वक देखा व सुना जा सकता है। इस प्रकार कम्पयूटर टैक्नोलॉजी में इन्टरनैट के माध्यम से प्रत्यक्ष-अप्रत्यक्ष रूप से संगीत के क्षेत्र में अपने महत्वपूर्ण योगदान को सिद्ध किया है। इस प्रकार वर्तमान संगीत का स्तर वृद्धिगत करने में कम्पयूटर का विशेष स्थान है परन्तु भाव प्रवणता जो संगीत का महत्वपूर्ण अंग है उस की हानि इससे न हो पाये इस पर भी ध्यान केन्द्रित करना चाहिए। यही कला की उन्नति नवीनता एवं उत्तमता के लिए आवश्यक भी है। 